IP Periodica Polytechnica

Mechanical Engineering

61(3), pp. 225-233, 2017

https://doi.org/10.3311/PPme.9890

Creative Commons Attribution (i)

RESEARCH ARTICLE

\section{Effects of Cone Angle and Inlet Blade Angle on Mixed Inflow Turbine Performances}

\author{
Mohammed Amine Chelabi ${ }^{1 *}$, Mohammed Kamel Hamidou ${ }^{1}$, \\ Mohammed Hamel $^{1}$
}

Received 14 August 2016; accepted after revision 31 January 2017

\begin{abstract}
The development of the aerofoil-shaped turbomachine blades is of prime importance for achieving the appropriate deflection of a three dimensional flow through desired angles, to work at the same degree of incidence and thereby providing the required performances for the specific machine. The sensitivity of the rotor to incidence effects and tendency of the flow to separate from one or the other blade surface have given rise to considerations of the optimum incidence angle and cone angle for a mixed inflow turbine by a numerical investigation using the ANSYS-CFX code. In order to keep the rotor in the same casing some geometrical parameters have been hold constant and the Bezier polynomial is used to generate the new shape of the rotor blade when changing the cone angle magnitude.
\end{abstract}

\section{Keywords}

turbomachine, blade, camberline, cone angle

\footnotetext{
${ }^{1}$ Laboratory of Applied Mechanics, Faculty of Mechanical Engineering, University of Science and Technology Mohamed Boudiaf-El Mnaouar, PO Box 1505 Bir E1 Djir 31000, Oran, Algeria
}

*Corresponding author, e-mail: Amine.chelabi@univ-usto.dz

\section{Introduction}

The mixed inflow turbines are suitable for many applications and particular attention is paid to systems where compact power sources are required, with higher boost pressure. Vehicle diesel engines use turbocharging and operate over a wide range of speeds and loads. Mixed inflow turbine geometry is designed by radially bending the leading edge of a radial turbine. This has the advantage to reduce flow path curvature and decrease formation of secondary flow generally found in the radial turbines. By altering the cone angle, it is then possible to achieve a non-zero value of the blade angle, thus causes the peak efficiency to shift to a lower velocity ratio magnitude $(\mathrm{U} / \mathrm{C}=064)$. When rotor blades are suitably shaped and properly oriented in the flow, the useful force acting on it is considerably larger. Thus, the effects of changing the blade angle and cone angle on the performance of a mixed inflow turbine are investigated by a numerical analysis. In order to get a better physical meaning of the cone angle. It is defined us the angle formed by the radial direction and any mixed inflow direction. There is no definitive optimum cone angle for a mixed flow rotor and different values are usually used. Nevertheless, the values used by researchers in the past are shown in Table 1 can be used as a basic reference.

Many numerical and experimental studies were carried out to determine the performances of mixed inflow turbine usable in the overfeeding of the internal combustion engines and to include/understand the phenomena in the course of their operation. The design approach of the mixed flow turbine was developed by a limited number of researchers in the world. Baines et al. [1] examined two mixed inflow turbines and achieved similar agreement with Wallace and Blair works. Abidat [2] and Abidat et al. [3] developed a new method of the blade profile generation by using the Bezier polynomials, showed that the Reducing of blade number for mixed-flow turbine with a constant blade angle from 12 to 10 leads to higher blade loading and results in about a $2 \%$ efficiency penalty. They were able to confirm a similar test result with Baines et al. [1]. Leonard et al. [4] studied the automotive turbocharger mixed flow turbine inlet geometry for off design performance. According 
to Leonard et al. [4] it is evident that the simple addition of a blade cone angle to a design alone is not adequate to yield efficiency improvements at low velocity ratio conditions. Furthermore, Bernhardt Lüddecke et al. [5] compared the efficiency between a mixed flow turbine and radial turbine for different rotational speeds, and showed that the blade speed ratio where optimum efficiency is reached is usually lower than the commonly quoted blade speed ratio of 0,7. Wallace et al. [6] used the one-dimensional analysis and the empirical models of losses of energy to calculate the optimum dimensions of a mixed inflow rotor. Moreover, a systematic approach to optimize the mixed flow turbines design was explained by the works of Chen and Baines; who attempted to minimize energy losses by reducing the rotor inlet velocity and rotor exit velocity. Chen and Baines [7] afterward finished that the mixed inflow turbine design can be optimized by setting the exit swirl angle to zero or some positive value, thereby balancing reduced internal loss and increased exit loss. Subrata Kr. Ghosh [8] presented design procedure of the turbine wheel of mixed flow impellers Abidat et al. [9] were studied the influence of the clearance between the rotor tips blades and the casing on the turbine performances and showed that the efficiency decreases with the clearance between the rotor blade tip and the casing.

Table 1 The result of past researchers for efficiency versus cone and inlet blade angle

\begin{tabular}{llll}
\hline Authors & $\delta_{2}\left[^{\circ}\right]$ & $\beta_{2 b}\left[^{\circ}\right]$ & $\eta$ \\
\hline Baines et al. [1] (experimentally) & 40 & 30 & 0.77 \\
Abidat et al. [2],[3] (experimentally) & 40 & 20 & 0.84 \\
& 30 & 10 & 0.73 \\
& & 20 & 0.72 \\
Leonard et al. [4] (Numerically) & 45 & 30 & 0.71 \\
& & 10 & 0.72 \\
& & 30 & 0.71 \\
& & 10 & 0.68 \\
& 60 & 20 & 0.66 \\
\hline
\end{tabular}

M. H. Padzillah et al. [10] studied numerically and experimentally the effect of flow angle on the characteristics of mixed flow turbine and showed that only part of the turbine span is operating under optimum condition. F.J. Wallace [11] presented in his Phd a symmetric approach to the design of radial inflow and mixed inflow turbines. Assim Hameed et al. [12] investigated the wake domain downstream of blade cascade with blowing coolant flow and found that the flow structure in the wake is dominated by very strong random vortices close to the suction side and the trailing edge, the wake zones decrease in life distance with decreasing in blowing ratio. Chan M.kim et al.
[13] analyzed the performance of mixed flow turbine and compared with the experimentally results. Sepehr Sanaye et al. [14] studied the flow around blade cross sections and predicted the corresponding noise emission, he used the Bezier polynomial for the optimization of airfoil shape computations. N Karamanis et al. [15] investigated the steady and unsteady performances of a mixed-flow turbocharger turbine with a constant blade inlet angle. Uswah et al. [16] optimized the hub and the shroud in order to increase the mixed inflow turbine efficiency.

A relationship (1) between the inlet blade angle, cone angle and camber angle has been developed by Whitfield and Baines [17].

$$
\tan \left(\beta_{2 b}\right)=\cos (\lambda) \operatorname{tang}(\Phi)
$$

There are currently several works and research on the Bezier Polynomial to facilitate and improve the adaptation of the schemes to the needs of the designer. Dušan Páleš et al. [18] explained in detail creation of the calculation algorithm together with the resulting program on Bezier Polynomial. Andrej Blejecl [19] presented the application of Bernstein-Bezier polynomials for smoothing of noisy data. Ferdous Ahmed Sohel et al. [20] defined and enhanced Bezier curve (EBC) models which seamlessly incorporate local information. Hong-Jie Cai et al. [21] proposed three new algorithms, in a unified approach, for the degree reduction of Bezier curves, approximating rational Bezier curves by Bezier curves and the degree reduction of rational Bezier curves respectively. F. Ghomanjani [22] applied the Bernstein's approximation on delay differential equations and delay systems with inverse delay that models these problems.

\section{Rotor shape generation}

The mixed inflow turbines with the rotor type A [2] shown in Fig. 1, defined with its constant blade angle, is under investigation.

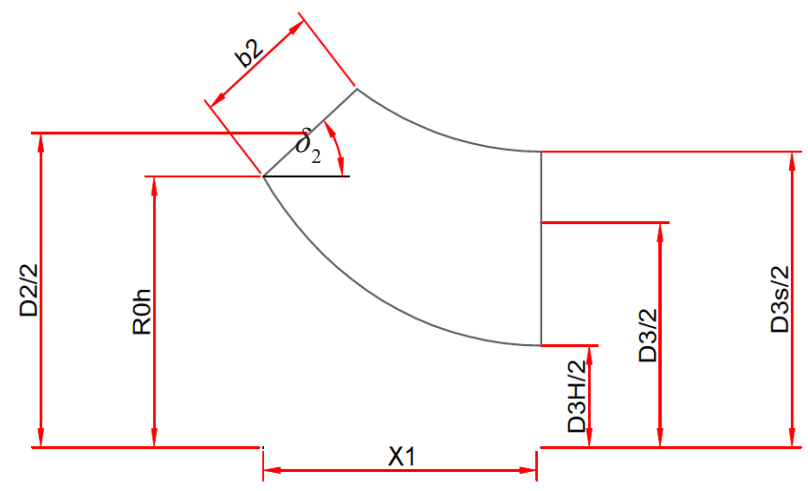

Fig. 1 The blade meridian view

One try to obtain the new rotor shapes by changing the cone angle values and keeping the same geometrical magnitude of the following parameters $\mathrm{b}_{2}, \mathrm{D}_{2}, \mathrm{X}_{1}, \mathrm{~b}_{2}, \mathrm{D}_{3 \mathrm{H}}, \mathrm{D}_{3 \mathrm{~s}}, \mathrm{D}_{3}$ in order to conserve the same casing. The Bezier polynomial is adopted for this purpose. The relations below are used (Eq. (2) and Eq. (3)). 


$$
\begin{aligned}
r & =(1-u)^{4} r_{0}+4 u(1-u)^{3} r_{1}+6 u^{2}(1-u)^{2} r_{c} \\
& +4 u^{3}(1-u) r_{2}+u^{4} r_{3} \\
x & =(1-u)^{4} x_{0}+4 u(1-u)^{3} x_{1}+6 u^{2}(1-u)^{2} x_{c} \\
& +4 u^{3}(1-u) x_{2}+u^{4} x_{3}
\end{aligned}
$$

To trace the hub and the shroud, it is necessary to calculate the coordinates of items $0,1, \mathrm{C}, 2$ and 3 given according to the blade dimensions in reference [23]. The blade shape for different cone angle are represented in Fig. 2.

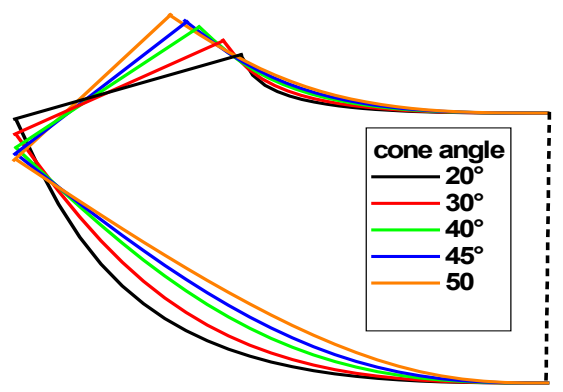

Fig. 2 Meridian blade view for different cone angle.

The curve of the leading edge is obtained by the following relations (Eq. (4) and Eq. (5)):

$$
\begin{gathered}
\theta=\theta_{\text {ref }}+\frac{1}{\sin \left(\delta_{2}\right)} \int_{x_{r e f}}^{x} \tan \left(\beta_{2 b}\right) \frac{d x}{r} \\
r=r_{0 h}+\left(x-x_{0 h}\right) \tan \left(\delta_{2}\right)
\end{gathered}
$$

To determine the remainder of the camberline, it is obligatory to calculate the coordinates of items $0,1, b, 2$ and 3 (see Fig. 3) given according to the blade dimensions in reference [23] where the Bezier polynomial is used. The following forms are applied (Eq. (6) and Eq. (7)):

$$
\begin{aligned}
x & =(1-u)^{4} x_{0}+4 u(1-u)^{3} x_{1}+6 u^{2}(1-u)^{2} x_{b} \\
& +4 u^{3}(1-u) x_{2}+u^{4} x_{3} \\
\theta & =(1-u)^{4} \theta_{0}+4 u(1-u)^{3} \theta_{1}+6 u^{2}(1-u)^{2} \theta_{b} \\
& +4 u^{3}(1-u) \theta_{2}+u^{4} \theta_{3}
\end{aligned}
$$

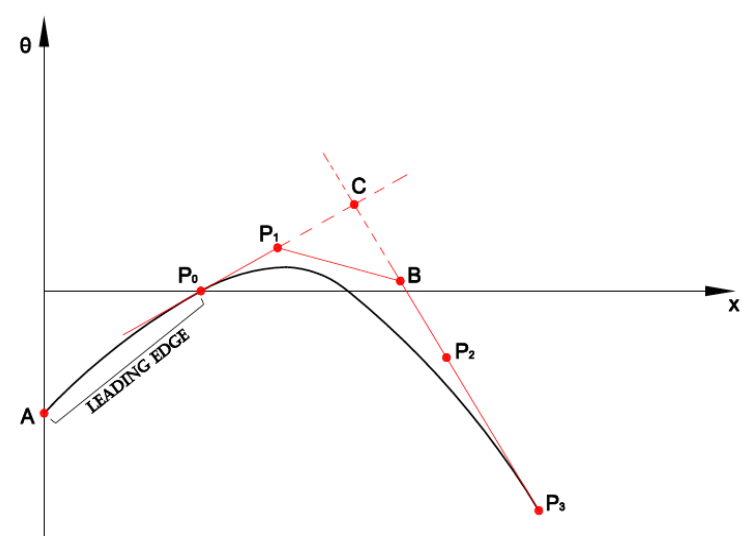

Fig. 3 Camberline generation
The three dimensional geometrical blade shapes for different cone angles at an inlet blade angle equals to $20^{\circ}$ are represented in Fig. 4.

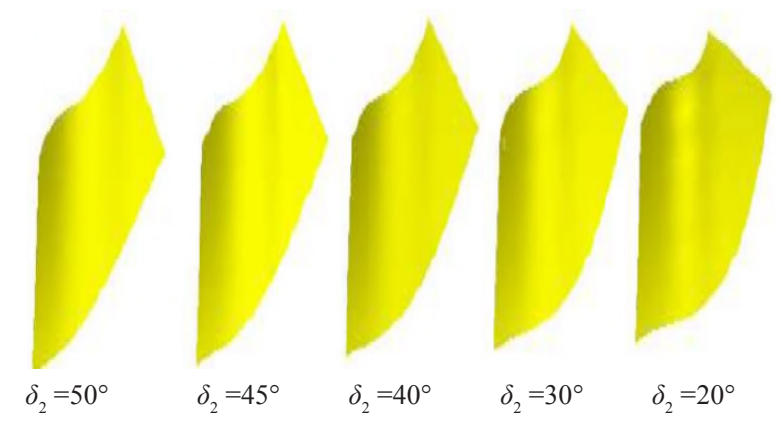

Fig. 4 Three dimensional geometrical shapes

It appears three dimensional changes in rotor shape, in curvatures with an enlarged hub which should allow a gradual energy transformations and a compressed shroud with a shorter flow path. Rotor blade surface calculations have been conducted for different cone angles to facilitate the result interpretations. Actually, due to the three dimensionality, larger cone angles result in smaller surfaces (see Table 2).

Table 2 The blade area in $\mathrm{mm}^{2}$ resulted for different cone angles and inlet blade angles

\begin{tabular}{llllll}
\hline$\delta_{2}$ & $20^{\circ}$ & $30^{\circ}$ & $40^{\circ}$ & $45^{\circ}$ & $50^{\circ}$ \\
\cline { 1 - 4 }$\beta_{2 \mathrm{~b}}$ & & & & & \\
\hline $0^{\circ}$ & 1050 & 1010 & 980 & 970 & 960 \\
$10^{\circ}$ & 1070 & 1020 & 990 & 980 & 962 \\
$20^{\circ}$ & 1130 & 1050 & 1000 & 990 & 956 \\
$30^{\circ}$ & 1200 & 1100 & 1030 & 1010 & 984 \\
\hline
\end{tabular}

Two different cases have been studied, the first one is concerned with a fixed volute exit area orientation with a variable rotor surface entrance. The cone angle is affecting the orientation of the rotor entrance and the inlet blade angle is varied. The second situation, the rotor cone angle is varied and the volute exit surface follows the orientation of the former. Both surfaces are parallel as shown on Fig. 5.

\section{Grid generations and numerical method}

The numerical solution of partial differential equations wants some discretization of the field into a group of points or basic volumes. The differential equations are approximated by a set of algebraic equations on this collection, and this algebraic equation system is then treated to produce a set of discrete values which approximates the solution of the partial differential system over the domain. The discretization of the field requires some union for the solution thereon to be efficient, i.e., it must be possible to readily identify the points or cells neighboring the computation site. Furthermore, the discretization 

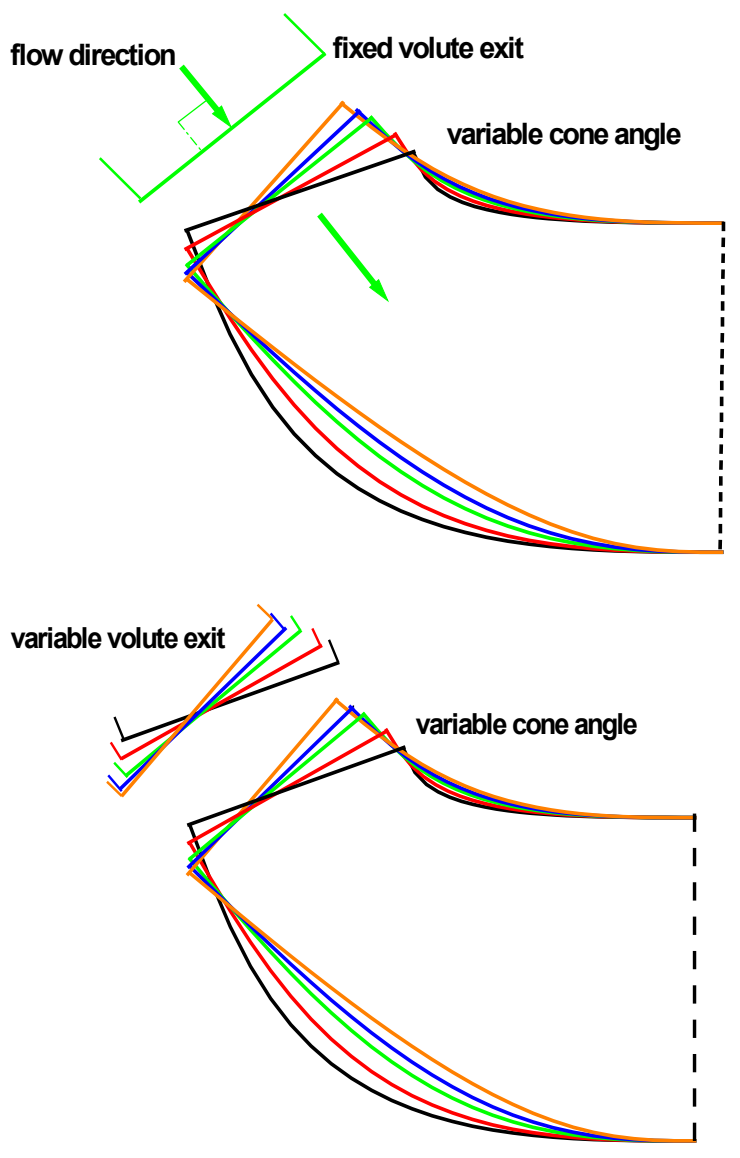

Fig. 5 Volute exit positions

must conform to the boundaries of the region in such a way that boundary conditions can be accurately represented. This organization is asked by a organize system, and the need for alignment with the boundary is reflected in the routine choice of cartesian coordinates for rectangular regions, cylindrical coordinates for circular regions, etc., to the extent of the handbook's resources. There exist two types of grid: the structured grid and the no structured grid .In this study, the unstructured hexahedral grid was used, because it copes well with turbomachine simulations. To carry out this grid, it is necessary to create a numerical field associated with the physical field. The grid is generated by the determination of the number of the nodes according to the three directions, starting from these operations. The grid obtained is represented in Fig. 6. To reach more precise results the grid meadows of walls is refined (see Fig. 7) in order to obtain more informations on the distribution of the thermodynamic parameters in the boundary layer. The determination of the geometry and the grid generation were made by ANSYS ICEM-CFD code. In our simulation one used ANSYS-CFX, the finite volume approach is adopted (or control volume) which is popular in CFD as a result, primarily, of two advantages. First, they ensure that the discretization is conservative, i.e., mass, momentum, and energy are conserved in a discrete sense. While this property can usually be obtained

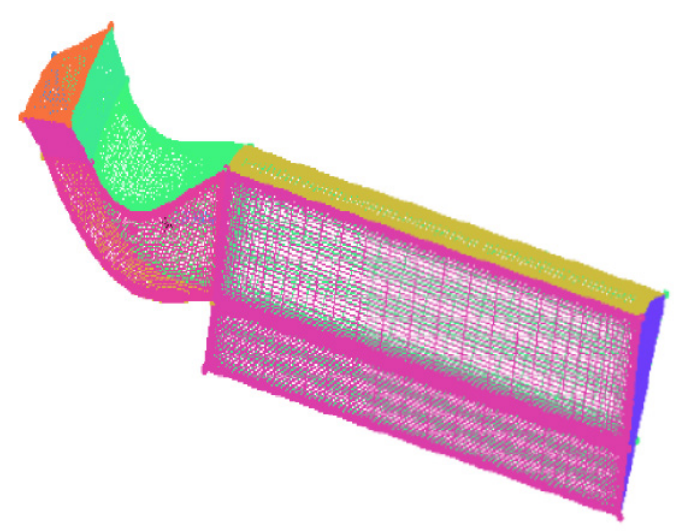

Fig. 6 No structured mesh presentation

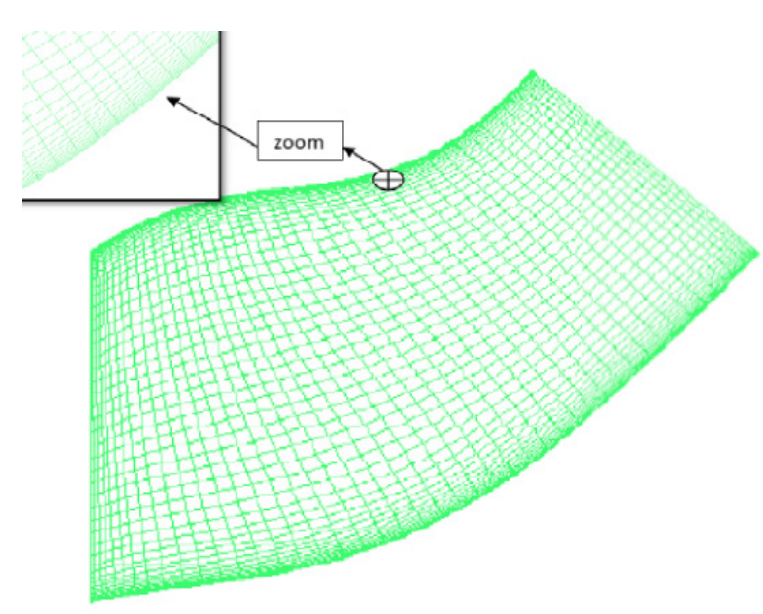

Fig. 7 The mesh refinement near the hub and shroud

using a finite-difference formulation, it is obtained naturally from a finite-volume formulation. Second, finite-volume method does not require a coordinate transformation in order to be applied on irregular meshes. As a result, it can be applied on unstructured meshes consisting of arbitrary polyhedral in three dimensions or arbitrary polygons in two dimensions. This increased flexibility can be used to great advantage in generating grids about arbitrary geometries.

\section{Flow simulations in a mixed inflow turbine}

A highly three dimensional, compressible, viscous flow in the mixed inflow turbine with rotor type $\mathrm{A}$ is investigated by solving numerically the Reynolds averaged equation of conservation. In all real flow situations the physical laws of conservation are relevant. These submit to the conservation respectively of mass (Eq. (8)), momentum (Eq. (9)) and energy (Eq. (10)). The equation of state (Eq. (11)) completes the set that desires to be solved if some or all of the parameters controlling the flow are unidentified.

$$
\begin{gathered}
\frac{\partial \rho}{\partial t}+\nabla(p \vec{v})=0 \\
\rho \frac{D \vec{V}}{D t}=\rho \vec{B}-\nabla P+\rho \vec{f}
\end{gathered}
$$




$$
\begin{gathered}
\frac{D e}{D t}+\frac{d\left(V^{2} / 2\right)}{d t}=\frac{d q}{d t}+\frac{d w_{e}}{d t} \\
p=\rho R T
\end{gathered}
$$

The flow through turbomachines flows is turbulent thus; it introduces new variables in averaged Navier-Stokes equations, to close this equations it necessary to introduce a turbulence model. The applied turbulence model is the stander $k-\varepsilon$; it is advised that the $y+$ value for the near wall node has to be in the range of 20 to 100 . This model is based on the eddy viscosity concept which assumes that the Reynolds stresses $-p \bar{u}_{i} \bar{u}_{j}$ can be expressed in terms of the mean velocity gradients and the eddy or turbulent viscosity $\mu_{t}$, in a manner analogous to the viscous stresses $\tau_{i j}$ for laminar Newtonian flows (see Eq. (12) and Eq. (13))

$$
\begin{gathered}
\tau_{i j}=\mu\left(\frac{\partial U_{j}}{\partial X_{i}}+\frac{\partial u_{i}}{\partial X_{j}}\right)-\frac{2}{3} \mu \delta_{i j} \frac{\partial U_{k}}{\partial X_{k}} \\
-p \overline{u_{i} u_{j}}=\mu_{t}\left(\frac{\partial U_{j}}{\partial X_{i}}+\frac{\partial u_{i}}{\partial X_{j}}\right)-\frac{2}{3} \mu_{t} \delta_{i j} \frac{\partial U_{k}}{\partial X_{k}}-\frac{2}{3} \delta_{i j} p_{k}
\end{gathered}
$$

This model assumes that the eddy viscosity $\mu_{t}$ is related to the turbulent kinetic energy $k$ and its dissipation rate $\varepsilon$ presented by the relation Eq. (14)

$$
\mu_{t}=p C_{\mu} \frac{k^{2}}{\varepsilon}
$$

Where $C_{\mu}=0.09$ and $k, \varepsilon$ are defined by the equations Eq. (15) and Eq. (16):

$$
\begin{aligned}
& \frac{\partial(p k)}{\partial t}+\nabla \cdot(p k \vec{U})=\nabla \cdot\left[\left(\mu+\frac{\mu_{t}}{\sigma_{k}}\right) \nabla k\right]+P_{k}-p_{\varepsilon} \\
& \frac{\partial(p \varepsilon)}{\partial t}+\nabla \cdot(p \varepsilon \vec{U})=\nabla \cdot\left[\left(\mu+\frac{\mu_{t}}{\sigma_{k}}\right) \nabla \varepsilon\right] \\
&+\frac{\varepsilon}{k}\left(C_{1 \varepsilon} P_{k}-C_{2 \varepsilon} \rho_{\varepsilon}\right)
\end{aligned}
$$

In this model $P_{k}$ is the turbulence production and $\sigma_{k}=1.00$, $\sigma_{\varepsilon}=1.30, C_{1 \varepsilon}=1.44, C_{2 \varepsilon}=1.92$ are constants determined experimentally.

\section{Grid generation solution dependency}

The mesh generation should be carefully treated in order to discard any dependency on the flow field solution in the resolution of the three dimensional compressible viscous flow. A refined grid generation is recommended in flow regions with high gradients. So that the solutions of the numeral simulation are not approximations, the analysis of the grids quality as its influence on the results is a fundamental point which deserves a special attention. The errors related to the grid must disappear for increasingly fine mesh, until asymptotically reaching numerical values independent of the size of the grids. Thus, to analyze the quality of the grid and its influence on the solution, four grids of 107244, 233844, 333372, and 415030 elements were tested on the rotor type A. The analysis of the graphs show that the number of elements does not have any influence on the torque and the mass flow rate (see Fig. 8), a negligible influence on the static pressure distribution around the rotor blade (see Fig. 9). On the other hand there exists a variation in the efficiency graph. The Fig. 8 shows that the optimal grid number is higher or equal to 333372 elements which is applied in the numerical simulations.

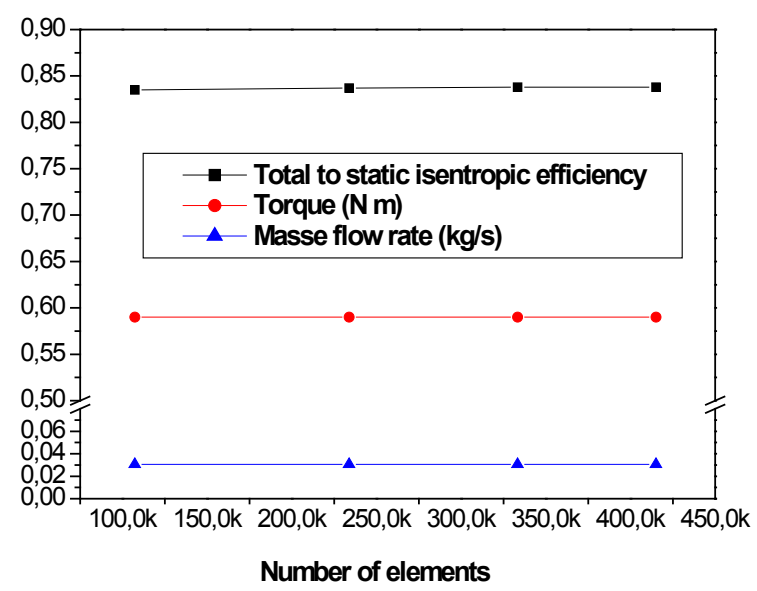

Fig. 8 Effect of element number on efficiency, torque and mass flow rate

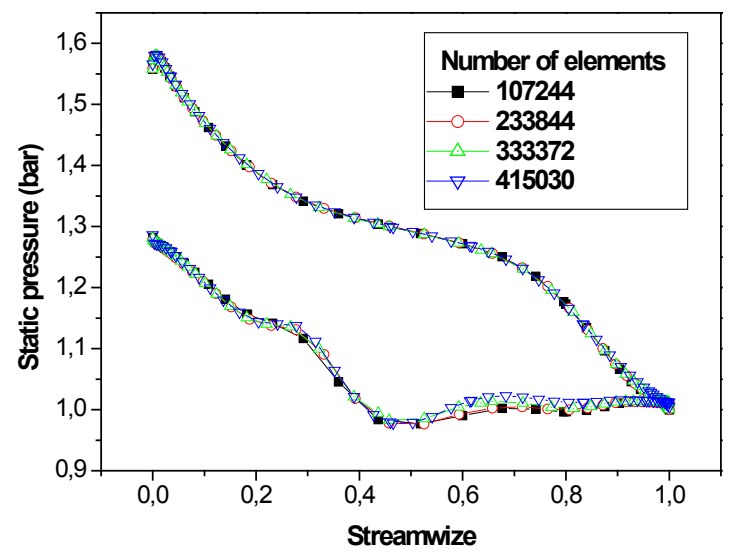

Fig. 9 Effect of element number on static pressure

\section{Numerical model validations}

The numerical validation is tested by the experimental results of Chen and Abidat [2] on rotor type A. The expansion pressure ratio defined as the inlet stagnation pressure over the exit static pressure; is represented along the blade axial direction for a rotational speed of $57900 \mathrm{rpm}$ and an absolute flow angle equals to $-13^{\circ}$. The results are shown in Fig. 10, a good agreement between numerical simulation and experimental results is observed. 


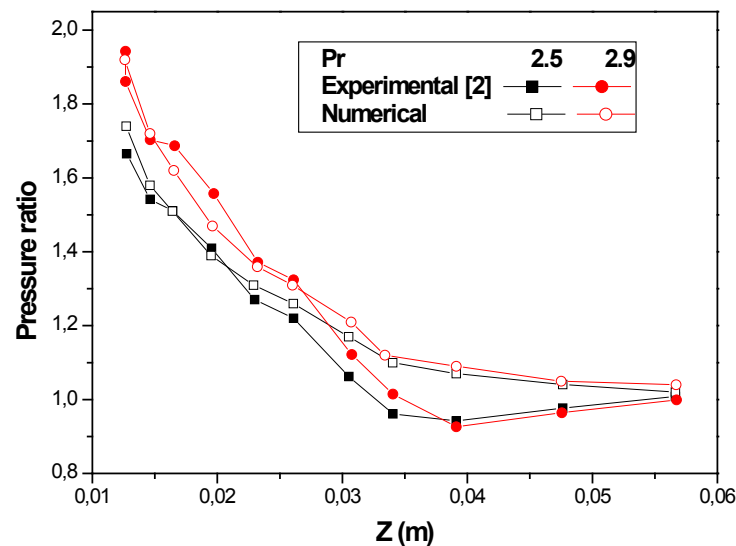

Fig. 10 Validation curves between experimental and numerical results

\section{Results and discussions}

The numerical simulations on the airfoil shaped blades for variable cone angles $\left(20^{\circ}, 30^{\circ}, 40^{\circ}, 45^{\circ}\right.$ and $\left.50^{\circ}\right)$ and different inlet blade angles $\left(0^{\circ}, 10^{\circ}, 20^{\circ}\right.$ and $\left.30^{\circ}\right)$ have revealed some instructive results linked with the turbine total to static efficiency and the pressure distribution around the rotor blade which is related to the loading effect.

The second point of interest in this study is a performance comparison between the fixed orientation of the volute exit case and the parallel surfaces ; volute exit - rotor inlet case; as shown in Fig. 5.

\subsection{The turbine total to static efficiency}

It is observed that the effect of the cone angle and the inlet blade angle on the turbine efficiency is obvious and not negligible. In the case of parallel volute exit (see Fig. 11), it is noticed that in the range of inlet blade angle between $0^{\circ}$ and $20^{\circ}$, all the concerned point except for the $50^{\circ}$ cone angles, the curves are around the level of the maximum efficiency. Once the inlet blade angle is increased over $20^{\circ}$, this indicates a fall of the efficiency which could be due to the fact that the flow can not adjust to the new direction, this causes a large incidence shock losses. Also, as the cone angle is raised, the efficiency is decreased because the fluid flow direction is tending to an axial direction in a centrifugal machine.

The fixed volute exit case on Fig. 12, shows a gradual decrease of the efficiency starting from the maximum value which corresponds to an inlet blade angle equals to zero. This confirms a great sensitivity of the efficiency with the inlet blade angle, which may due to a less flow guidance toward the rotor blade. The effect of the cone angle is reversed compared to the parallel volute case, since the surface of the blade is diminishing (see Table 2) the friction losses become smaller.

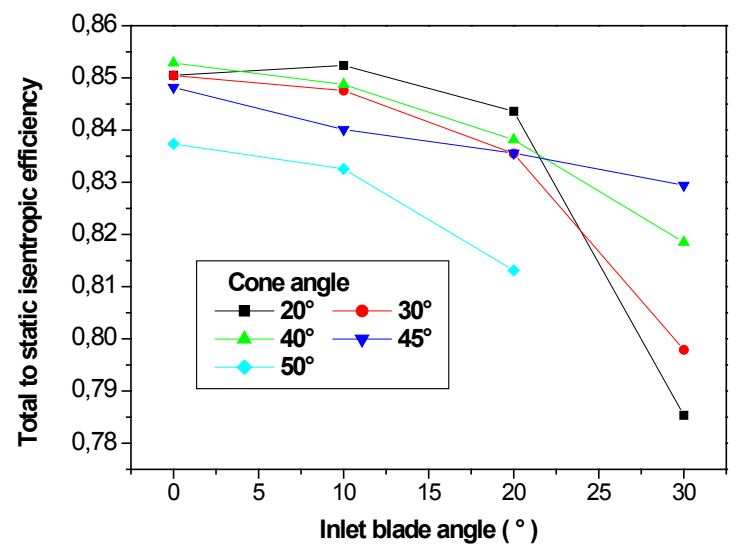

Fig. 11 The total to static efficiency for parallel volute exit case

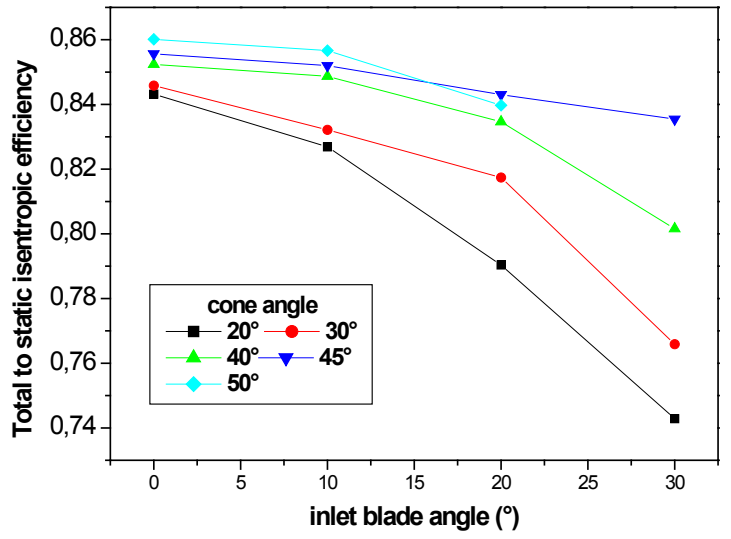

Fig. 12 The total to static efficiency for fixed volute exit case

\subsection{The static pressure distribution around the blade at the mean radius}

The pressure distributions around the rotor blades, for different inlet blade angles and cone angles for both cases are presented. Each curve is specific to a cone angle magnitude, with a varying inlet blade angle.

The observation of numerical results for both cases; non parallel surface areas and parallel one; show that, the magnitude of blade angle equals to $10^{\circ}$ represents an optimal value since it leads to a large and more uniform pressure distribution at any value of cone angle (see Figs. 13-22). Also for both cases; concerned with the pressure distribution at the cone angle $50^{\circ}$; the curves obtained for different values of blade angles present a trend towards coincided curves, which means a slight dependency of the pressure contours on the blade angle. There is a better blade loading, on account of the larger static pressure difference between the suction side en the pressure side.

Apparently, the benefit acquired whit parallel surfaces: volute-rotor, overcomes the losses incurred by a large blade surface area. 


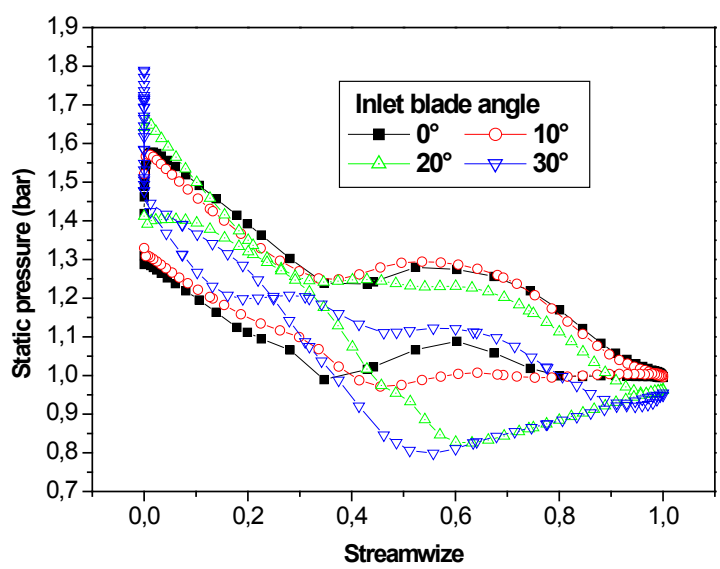

Fig. 13 The static pressure distribution around of the blade at the mean radius for $20^{\circ}$ cone angle of fixed volute

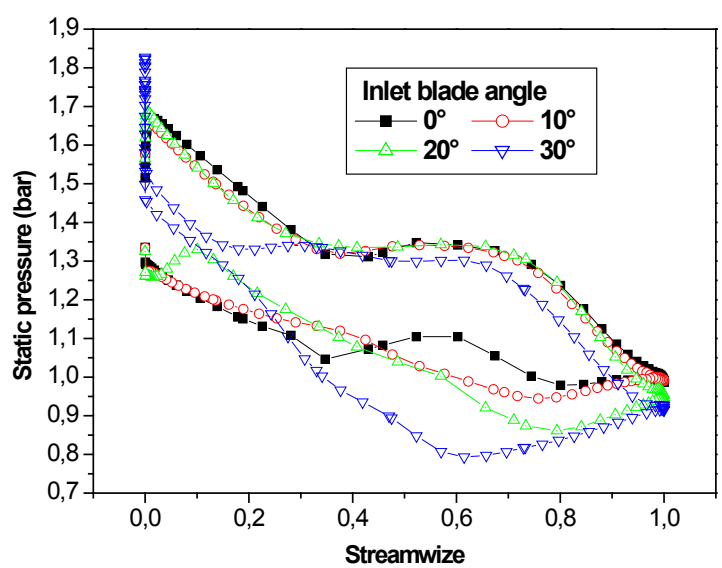

Fig. 14 The static pressure distribution around of the blade at the mean radius for $20^{\circ}$ cone angle of parallel volute

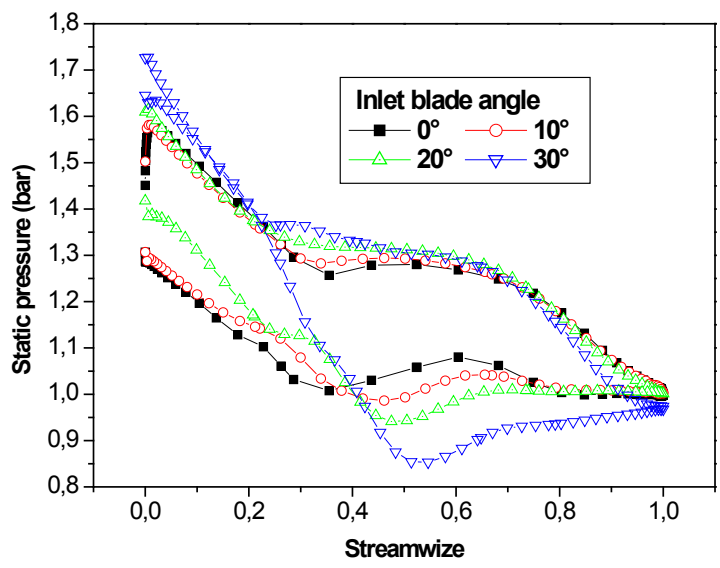

Fig. 15 The static pressure distribution around of the blade at the mean radius for $30^{\circ}$ cone angle of fixed volute

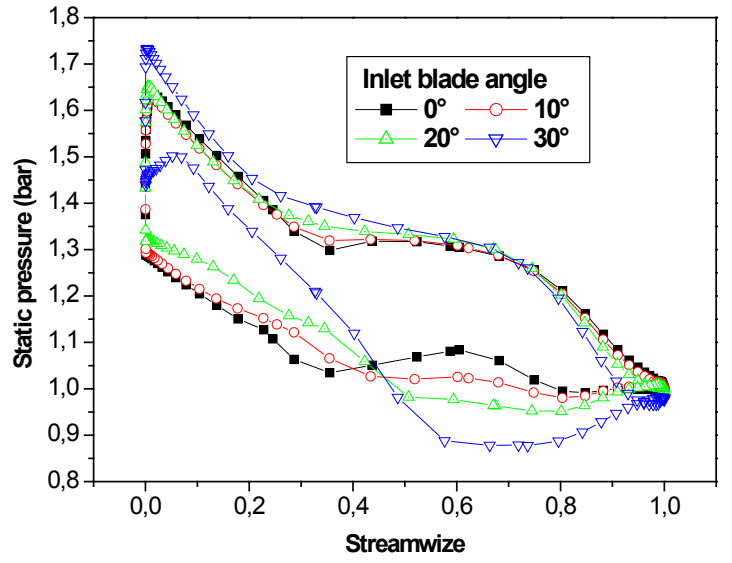

Fig. 16 The static pressure distribution around of the blade at the mean radius for $30^{\circ}$ cone angle of parallel volute

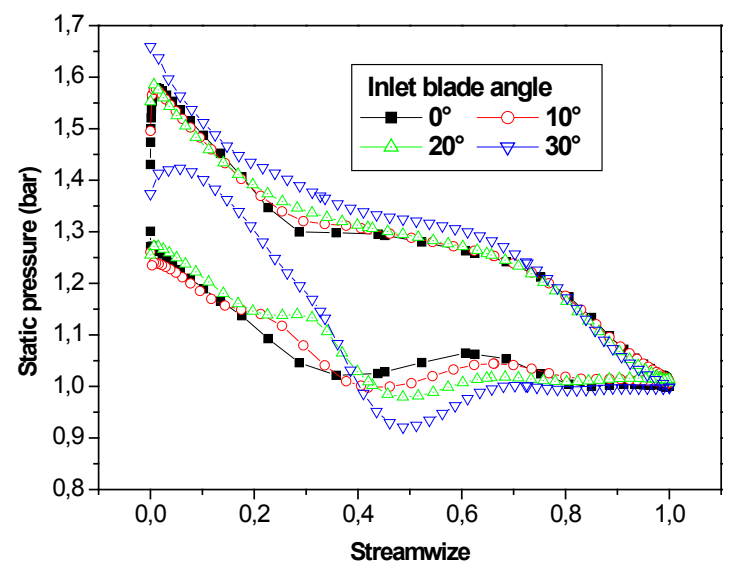

Fig. 17 The static pressure distribution around of the blade at the mean radius for $40^{\circ}$ cone angle of fixed volute

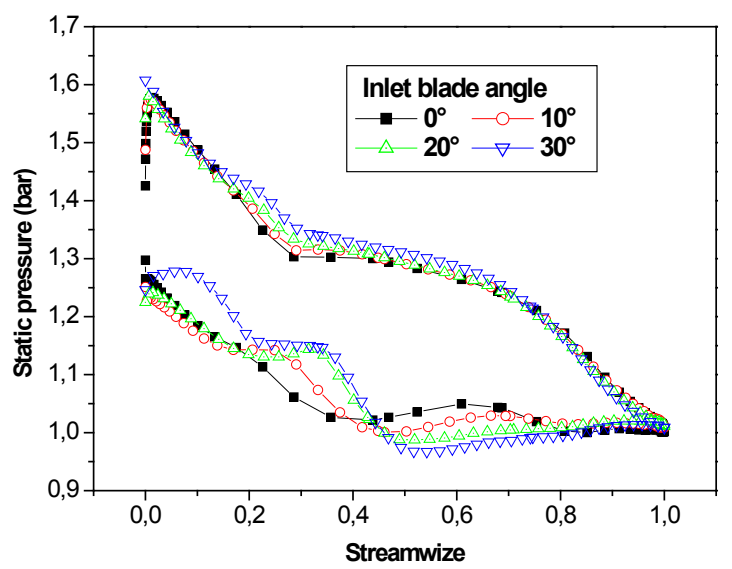

Fig. 18 The static pressure distribution around of the blade at the mean radius for $45^{\circ}$ cone angle of fixed volute 


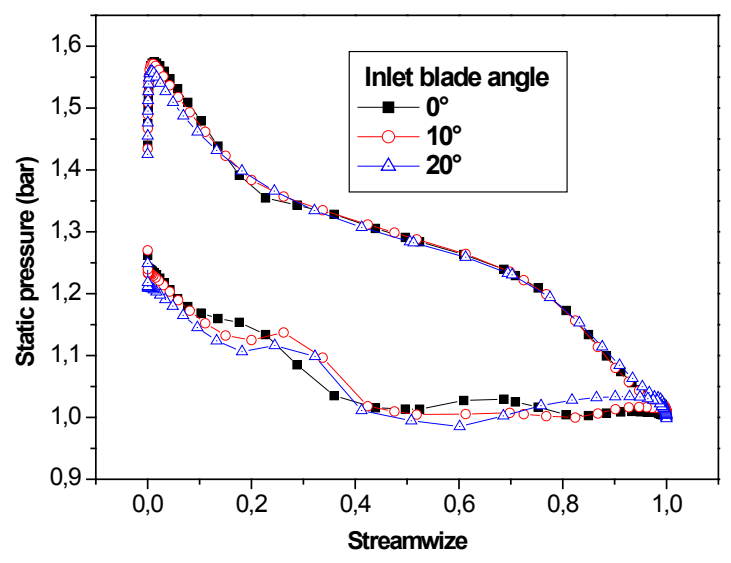

Fig. 19 The static pressure distribution around of the blade at the mean radius for $50^{\circ}$ cone angle of fixed volute

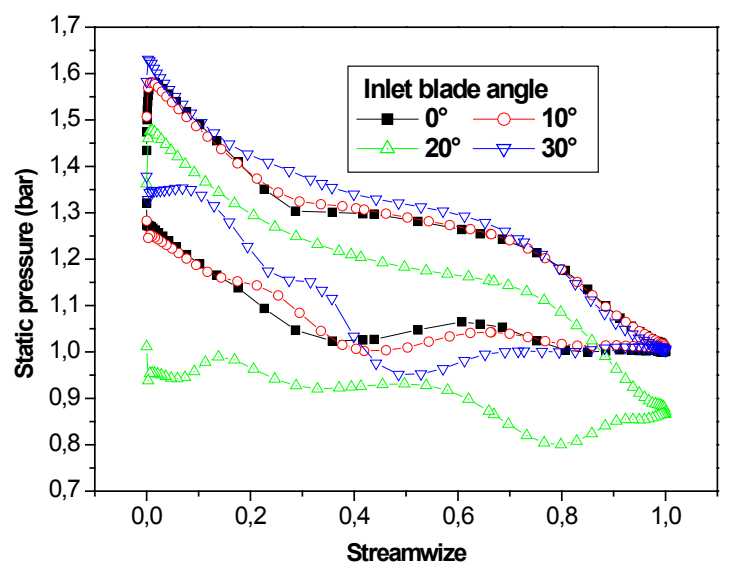

Fig. 20 The static pressure distribution around of the blade at the mean radius for $40^{\circ}$ cone angle of parallel volute

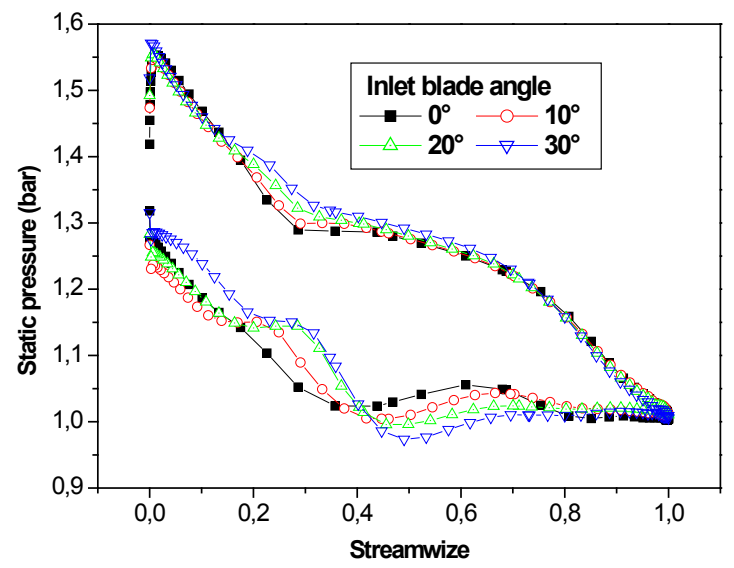

Fig. 21 The static pressure distribution around of the blade at the mean radius for $45^{\circ}$ cone angle of parallel volute

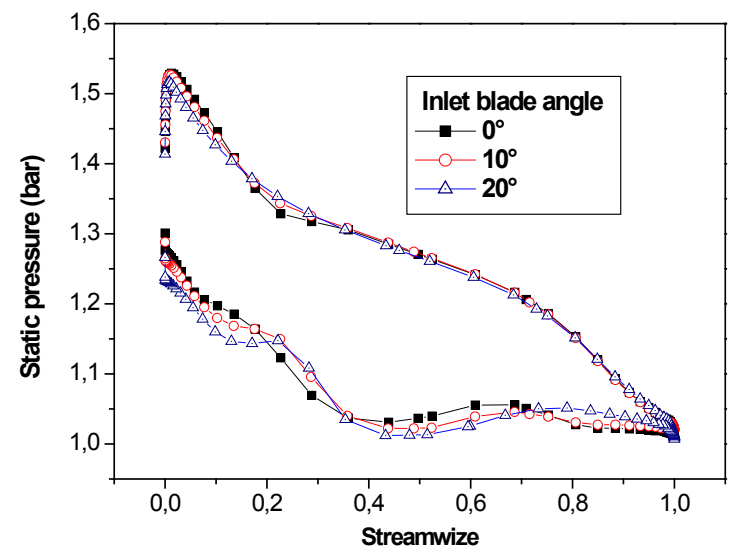

Fig. 22 The static pressure distribution around of the blade at the mean radius for $50^{\circ}$ cone angle of parallel volute

\section{Conclusion}

The results of a numerical prediction for a mixed inflow turbine under different inlet blade angles and cone angles are presented and discussed in this paper. Two cases are treated, the first one, the volute exit area orientation is hold fixed and the rotor inlet is varied with different values of cone angles. The second one, both surface areas are parallel. The benefit with regard to a $10^{\circ}$ blade angle, a large and more uniform pressure distribution around the rotor blade is obtained for any value of cone angle. The striking results are linked to the $50^{\circ}$ cone angle, which show almost no dependency of the pressure distribution on the blade angle. The maximum efficiency presents opposite trends between the two cases, the largest cone angle for the optimum efficiency and inversely. Eventually a fair compromise solution can be found. A less number of blades is suggested for a cone angle of $20^{\circ}$ in the case of parallel surfaces due to a large surface, weight, inertia and a wide range of operation for maximum efficiency is remarked. But the first case, with fixed volute exit seems to be more practical; without the penalty of varying the exit casing. Also leading to a larger value of the optimum efficiency, but for a one specific operating point.

\section{Nomenclature}

$\mathrm{D}_{2} \quad$ Mean diameter at rotor inlet

$b_{2} \quad$ Blade height at rotor inlet

$\delta_{2} \quad$ Cone angle at rotor inlet

$D_{3} \quad$ Exducer hub diameter

$D_{3 S} \quad$ Exducer tip diameter

$X 1 \quad$ Length of the rotor

$\theta \quad$ Camber angle

$\theta_{\text {ref }} \quad$ Reference camber angle

$X_{\text {ref }} \quad$ Reference axial distance of the blade

$\Phi \quad$ The inlet blade angle in the axial and tangent plan

$\lambda \quad$ The flow cone angle

$\eta \quad$ efficiency

$\beta_{2 b} \quad$ Mean blade angle at rotor inlet

$R_{0 h} \quad$ The radius at the tip rotor inlet 


$\begin{array}{ll}X_{0 h} & \text { The axial distance for the initial point of the hub } \\ D_{3} & \text { Exducer root mean square diameter } \\ \mathrm{X} & \text { Axial polar variable } \\ \mathrm{r} & \text { Radial polar variable } \\ \mathrm{u} & \text { variable between o and } 1 \\ \mathrm{p} & \text { Density } \\ \vec{V} & \text { Absolute velocity } \\ \mathrm{t} & \text { time } \\ \vec{B} & \text { body Forces } \\ \nabla P & \text { Pressure forces } \\ \vec{f} & \text { Friction forces } \\ \mathrm{e} & \text { Specific internal energy } \\ \mathrm{q} & \text { Heat transfer energy } \\ \mathrm{W}_{\mathrm{e}} & \text { The specific external force work } \\ \mathrm{P} & \text { pressure } \\ \mathrm{T} & \text { Temperature } \\ \mathrm{R} & \text { Perfect gas constant }\end{array}$

\section{References}

[1] Baines, N. C., Wallace, F. J., Whitfield, A. "Computer Aided Design of Mixed-Flow Turbines for Turbochargers." Journal of Engineering for Power. 110(3), pp. 440-448. 1979. https://doi.org/10.1115/1.3446597

[2] Abidat, M., Chen, H., Banes, N. C. "Design of a highly loaded mixed flow turbine." Proceedings of the Institution of Mechanical Engineers, Part A: Journal of Power and Energy. 206(2), pp. 95-107. 1992. https://doi.org/10.1243/PIME_PROC_1992_206_016_02

[3] Chen, H., Abidat, M., Baines, N. C., Firth, M. R. "The Effects of Blade Loading In Radial And Mixed Flow Turbines." In: ASME 1992 International Gas Turbine and Aeroengine Congress and Exposition. Volume 1: Turbomachinery. Cologne, Germany, Jun. 1-4, 1992. p. 6. https://doi.org/10.1115/92-GT-092

[4] Leonard, T., Spence, S., Early, J., Filsinger, D. "A numerical study of automotive turbocharger mixed flow turbine inlet geometry for off design performance." IOP Conference Series: Materials Science and Engineering. 52(4), p. 042012. 2013. https://doi.org/10.1088/1757-899X/52/4/042012

[5] Lüddecke, B., Filsinger, D., Ehrhard, J. "On Mixed Flow Turbines for Automotive Turbocharge Rapplications." International Journal of Rotating Machinery. 2012, Article ID 589720. 2012.

https://doi.org/10.1155/2012/589720

[6] Wallace, F. J., Baines, N. C, Whitfield, A. "A Unified Approach To One Dimensional Analysis And Design Of Radial And Mixed Flow Turbines" In: ASME 1976 International Gas Turbine and Fluids Engineering Conference. Volume 1B: General. New Orleans, Louisiana, USA, Mar. 2125, 1976. pp. V01BT02A035. https://doi.org/10.1115/76-GT-100

[7] Chen, H., Baines, N. C."Analytical optimization design of radial and mixed flow turbines." Proceedings of the Institution of Mechanical Engineers, Part A: Journal of Power and Energy. 206(3), pp. 177-187. 1992. https://doi.org/10.1243/PIME_PROC_1992_206_028_02

[8] Ghosh, S. K."A numerical model for the design of a mixed flow cryogenic turbine" International Journal of Engineering, Science and Technology. 2(1), 2010.
[9] Abidat, M., Hamidou, M. K., Hachemi, M., Hamel, M., Litim, S. A. "Performance prediction of a mixed flow turbine." Mechanics \& Industry. 9, pp. 71-79. 2008. https://doi.org/10.1051/meca:2008009

[10] Padzillah, M. H., Rajoo, S., Martinez-Botas, F. "Experimental and Numerical Investigation on Flow Angle Characteristics of an Automotive Mixed Flow Turbocharger Turbine." Jurnal Teknologi (Sciences \& Engineering). 77(8), pp. 7-12. 2015. https://doi.org/10.11113/jt.v77.6148

[11] Wallace, F. J. "A symmetric approach to the design radial and mixed inflow turbines." library royal aircraft establishment bedford cp.no1180

[12] Yousif, A. H., Shriffe, A. S. "Mixing losses investigation downstream of turbine blade cascade with coolant flow blowing." Journal of Engineering Science and Technology. 6(2), pp. 161-178. 2011.

[13] Kim, C. M., Civinkas, K. C. "An aerodynamic analysis of a mixed inflow turbine." NASA technical memorandum, 106674.

[14] Sanaye, S., Hassanzadeh, A. "Multi-objective optimization of airfoil shape for efficiency improvement and noise reduction in small wind turbines." Journal of Renewable and Sustainable Energy. 6(5), 2014. https://doi.org/10.1063/1.4895528

[15] Karamanis, N., Martinez-Botas, R. F. "Mixed-flow turbines for automotive turbochargers: steady and unsteady performance." International Journal of Engine Research. 3(3), pp. 127-138. 2002. https://doi.org/10.1243/14680870260189253

[16] Khairuddin, U., Costall, A. W., Martinez-Botas, R. F. "Influence of geometrical parameters on aerodynamic optimization of a mixed-flow turbocharger turbine." In: ASME Turbo Expo 2015: Turbine Technical Conference and Exposition, Volume 2C: Turbomachinery. Montreal, Quebec, Canada, Jun. 15-19, 2015. p. 15. https://doi.org/10.1115/GT2015-42053

[17] Whitfield, A., Baines, N. C. "Design of Radial Turbomachines." Longman, England, 1990.

[18] Páleš, D., Redl, J. "Bezier curve and its application" Mathematics in Education, Research and Applications. 1(2), pp. 49-55. 2015. https://doi.org/10.15414/meraa.2015.01.02.49-55

[19] Blejec, A. "Bézier Curves: Simple Smoothers of Noisy Data" In: Ferligoj, A., Kramberger, A. (eds) Developments in Statistics and Methodology. FDV, Ljubljana. 1993.

[20] Sohel, F. A., Karmakar, G. C., Dooley, L. S., Arkinstall, J. "Enhanced Bezier curve models incorporating local information." In: IEEE International Conference on Acoustics, Speech and Signal Processing (ICASSP'05), Philadelphia, PA, Mar. 18-23. 2005, pp. iv/253-iv/256 Vol. 4. https://doi.org/10.1109/ICASSP.2005.1415993

[21] Cai, H-J., Wang, G-J. "Constrained approximation of rational Bézier curves based on a matrix expression of its end points continuity condition." Computer-Aided Design. 42(5), pp. 495-504. 2010. https://doi.org/10.1016/j.cad.2009.12.008

[22] Ghomanjani, F., Farahi, M. H., Kılıçman, A., Kamyad, A. V., Pariz, N. "Bezier Curves Based Numerical Solutions of Delay Systems with Inverse Time." Mathematical Problems in Engineering. Vol. 2014, article id 602641, 16 pages. https://doi.org/10.1155/2014/602641

[23] Abidat, M. "Design and testing of a highly loaded mixed flow turbine." PhD Thesis. Imperial College London. 1991. 